\title{
Pancreatic pseudocyst haemorrhage presenting as a bleeding duodenal ulcer
}

\author{
D.J.J. Muckart and P. Bade
}

Department of Surgery, University of Natal, P.O. Box 17039, Congella, 4013, Durban, Republic of South Africa

Summary: We present a case of upper gastrointestinal haemorrhage where the preoperative endoscopic findings suggested a duodenal ulcer as the cause. Although at operation this proved to be the site of bleeding, the source was found to be the splenic artery in the base of a pancreatic pseudocyst.

\section{Introduction}

Peptic ulceration is the commonest pathology causing upper gastrointestinal haemorrhage. Endoscopy has increased the diagnostic yield and has demonstrated well recognized stigmata which indicate those patients who require surgery to prevent ongoing or repeated bleeds. ${ }^{1-3}$ In the majority of patients this examination reveals the exact pathology. We present an unusual case of upper gastrointestinal bleeding in whom the endoscopic findings were conclusive of duodenal ulceration but where the source of haemorrhage was from a pancreatic pseudocyst.

\section{Case report}

A 58 year old European male was admitted with a one-week history of melaena, a single episode of haematemesis, and a 3-week history of central abdominal pain, anorexia and weight loss. He confessed to a past history of heavy alcohol consumption but denied any recent intake. In order to relieve his abdominal pain he had been taking large amounts of paracetamol.

On examination the patient was pale and distressed. He was normotensive but had a tachycardia of 110 beats/minute. Abdominal palpation revealed no masses, a $2 \mathrm{~cm}$ hepatomegaly, and mild epigastric tenderness. Rectal examination confirmed melaena stool. Investigations on admission were: haemoglobin $10.8 \mathrm{~g} / \mathrm{dl}$; haematocrit $32 \%$; amylase $175 \mathrm{IU}$. The following day the haemoglobin dropped to $8.1 \mathrm{~g} / \mathrm{dl}$ and the haematocrit to $24 \%$. Upper gastrointestinal endoscopy demonstrated an active duodenal ulcer with evidence of recent bleeding but no visible vessel.

\footnotetext{
Correspondence: D.J.J. Muckart, F.R.C.S.
}

Accepted: 29 March 1989
Despite transfusion of 5 units of blood the haemoglobin failed to rise above $10 \mathrm{~g} / \mathrm{dl}$ and he continued to pass melaena stools. In common with other surgical units our policy for bleeding duodenal ulcers is to recommend surgery for all patients requiring 5 or more units of blood to maintain adequate haemoglobin levels, and this, in conjunction with the endoscopic findings indicated the need for surgical intervention.

On opening the peritoneal cavity, the stomach was found to be full of blood and both stomach and duodenum were pushed forward by a retroperitoneal mass. A standard pylorotomy was performed to obtain control of bleeding prior to definitive surgery. Situated on the posterior wall of the duodenal bulb was a large blood clot. This was removed by suction in order to visualize the ulcer base, but instead of finding the expected vessel in the base, the nozzle of the sucker immediately entered the lesser sac, removing large amounts of blood clot in the process. It was decided to explore the lesser sac by dividing the gastro-colic omentum. This was done with considerable difficulty due to a large amount of surrounding inflammation. On entering the sac, all blood clot was evacuated but no source of haemorrhage could be identified. Digital exploration revealed a communication with a further cavity, also full of clotted blood, extending toward the splenic hilum. Upon removing the exploring finger, profuse arterial bleeding ensued from the second cavity. The cavity was therefore opened, clot evacuated, and the bleeding found to be emanating from the splenic artery in the base of this cavity (Figure 1). The artery was ligated with immediate control of haemorrhage. Due to the necessary mobilization of the stomach to gain access to the lesser sac, the perforated posterior ulcer was now in free communication with the general peritoneal cavity. A 


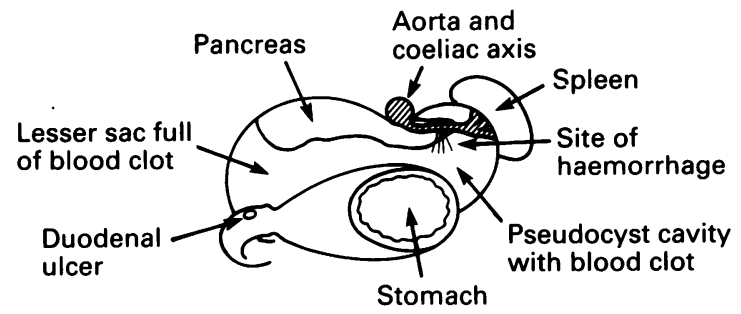

Figure 1 Transverse section through supra-colic compartment.

truncal vagotomy and polya gastrectomy was therefore performed with closure of the duodenal stump. The pseudocyst cavity and the duodenal stump were drained externally.

Post-operatively the patient was managed in the intensive care unit. He developed a low output fistula from the duodenal stump which responded to total parenteral nutrition and dried completely by the tenth post-operative day. The patient was discharged from in-patient care on the twenty-second day and at follow-up one and 3 months later was clinically well.

Biopsies from the two cavities confirmed the operative impression of an infected pseudocyst, and histology of the excised portion of the duodenum was consistent with peptic ulceration.

\section{Discussion}

Haemorrhagic complications associated with chronic pancreatitis are becoming increasingly well recognized. In those patients with proven pancreatitis and pseudocyst formation complicated by upper gastrointestinal haemorrhage, angiography and embolization have produced the best results. ${ }^{4}$ In the majority of these cases the source of bleeding has been identified

\section{References}

1. McLeod, I.A. \& Mills, P.R. Factors identifying the probability of further haemorrhage after acute gastrointestinal haemorrhage. Br J Surg 1982, 69: 256-258.

2. Griffiths, W.J., Neumann, D.A. \& Welsh, J.D. The visible vessel as an indicator of uncontrolled or recurrent gastrointestinal haemorrhage. $N$ Engl $J$ Med 1979, 300: $1411-1413$.

3. Foster, D.N., Miloszewski, K.J.A. \& Losowsky, M.S. Stigmata of recent haemorrhage in diagnosis and prognosis of upper gastro-intestinal bleeding. Br Med J 1978, 1: $1173-1177$.

4. Huizinga, W.K.J., Kalideen, J.M. \& Bryer, J.V. Control of major haemorrhage associated with pancreatic pseudocysts by transcatheter arterial embolisation. $B$ r $J$ Surg 1984, 71: 133-136. arising from vessels originating from the coeliac axis, the commonest source being the splenic artery.

Haemorrhage into the gastrointestinal tract may occur via two pathways. Firstly, the false aneurysm may erode through the intestinal wall, and secondly, the bleeding pseudocyst may communicate with the pancreatic duct producing haemosuccus pancreaticus. This latter route is favoured by aneurysms of the splenic artery ${ }^{5,6}$ and direct communication with the intestine is a rarity although erosion into the posterior wall of the stomach has been reported. ${ }^{7}$

Spontaneous rupture of a pancreatic pseudocyst is uncommon, and rupture into the duodenum is rare. The combination of haemorrhage from the splenic artery into a pseudocyst followed by spontaneous rupture into the duodenum is not documented. Reasons for the anatomical site of spontaneous rupture into the intestinal tract directly have been attributed to chance, increased intra-abdominal pressure, trauma, and decreased local tissue resistance. ${ }^{8.9}$ There is little doubt that in this case the last mentioned factor must be highly pertinent, rupture having occurred through the base of a posterior duodenal ulcer in an already weakened duodenal wall.

In the light of the endoscopic findings and clinical presentation, the surgical approach to this patient was fully justifiable. However, if it had been recognized that the patient was suffering from chronic pancreatitis with pseudocyst formation then angiography, despite the endoscopic findings, should have been the procedure of choice. Although common things occur commonly, and because many patients with alcoholrelated pancreatitis will also suffer peptic ulceration as a result of dietary habit, haemorrhage from a source other than a documented peptic ulcer must always be borne in mind in this group of patients. If any doubt exists as to the source of bleeding, then angiography is strongly recommended prior to any surgical intervention.

5. Bivins, B.A., Sachatello, C.R., Chuang, V.P. et al. Haemosuccus pancreaticus; gastro-intestinal haemorrhage due to rupture of a splenic artery aneurysm into the pancreatic duct. Arch Surg 1978, 113: 751-753.

6. Hall, R.I., Lavelle, M.I. \& Venables, C.W. Chronic pancreatitis as a cause of gastro-intestinal bleeding. Gut 1982, 23: 250-255.

7. Stroud, W.H., Cultoen, J.W. \& Anderson, M.C. Haemorrhagic complications of severe pancreatitis. Surgery 1981, 90: $657-665$.

8. Littman, R., Pochaczevsky, R. \& Richter, R.M. Spontaneous rupture of a pancreatic pseudocyst into the duodenum. Arch Surg 1970, 100: 76-78.

9. Shatney, D.H. \& Sosin, H. Spontaneous perforation of a pancreatic pseudocyst into the colon and duodenum. Am J Surg 1973, 126: 433-438. 